\title{
OUR EXPERIENCE WITH DOUBLE METATARSAL OSTEOTOMY IN THE TREATMENT OF HALLUX VALGUS
}

\author{
Pradeep George Mathew, Pavel Šponer, Jaroslav Pavlata, Haroun Hassan Shaikh
}

\begin{abstract}
Charles University in Prague, Faculty of Medicine and University Hospital in Hradec Králové, Czech Republic: Department of Orthopaedic Surgery

Summary: Adolescent hallux valgus (HV) is a progressive deformity of adolescent age consisting of metatarsus primus varus and hallux valgus. It has a high recurrence rate after conventional surgical correction. Ten feet in nine patients (two males, seven females) were treated surgically with the Peterson Newman bunion procedure, with a minimum follow-up of one year. During the final follow-up all these patients had no complaints of pain, joint stiffness or limping. Even though the patients had some mild loss of range of movements at the MTP joints 4- $6^{\circ}$ compared to preoperative value, it did not cause any functional impairment and all were satisfied with the final outcome. The double ostetomy for treatment of hallux valgus is technically precise procedure, provides excellent correction and stability and has low rate of recurrence of deformity. We had an excellent outcome in 10 feet in our study without residual deformity or complications.
\end{abstract}

Key words: Hallux valgus; Double metatarsal osteotomy; Adolescent age

\section{Introduction}

Adolescent hallux valgus is a progressive deformity of adolescent age consisting of metatarsus primus varus and hallux valgus (HV). The two fundamental elements in this condition are abduction and pronation of the hallux and adduction of the first metatarsal. Patients with this deformity often complain of pain and redness at the site of the prominent first metatarsal head, difficulty wearing peer group shoes as the foot is broader, and altered cosmesis. Parents of these patients are concerned about the progression of the deformity. More than 130 operations have been described for bunions suggesting that a universally satisfactory operation is not available $(7,23,27,28,30)$.

Diagnosis of HV can be made from patient's history and clinical examination, but may require radiographic studies, especially to assess the articulating surfaces of the metatarsophalangeal (MTP) joint and for surgical planning. Physical findings associated with $\mathrm{HV}$ can include bursitis in the area of the MTP joint, hammertoe deformity of the lesser toe, callus formation under the second metatarsal head due to altered weight-bearing and the development of osteoarthritis of the MTP joint $(3,13,31)$. There are a number of radiographic criteria used to assess the degree of HV. First, the status and condition of the articulating surfaces of the MTP joint should be inspected. Second, the HV angle, which is the angle formed by the intersection of the longitudinal axes of the diaphysis of the first metatarsal and the proximal phalanx, should be measured. An angle greater than 20 degree is considered abnormal. Thirdly, the intermetatarsal angle, which is the angle between the first and second metatarsal bones, should normally be between 5-8 degrees (18).

Initial treatment involves shoe wear modifications, such as wearing shoes with a wide toe box, low heel and insole for support of the forefoot $(6,20,29)$. This approach is only useful to minimize pain and irritation at the site of deformity. In adolescents with HV despite the use of well-fitting shoes there is still progression of hallux valgus deformity (13). Surgery for adolescent hallux valgus has been associated with a high rate of recurrence $(1,31)$ and poor results, including stiffness of the metatarsophalangeal (MTP) joint and persistent pain (3). Surgical correction of HV should be indicated when pain is associated with moderate to severe hallux valgus deformity and eventually increased intermetatarsal angle.

The aim of the study was to evaluate the clinical and radiological results of double metatarsal osteotomy in patients with hallux valgus.

\section{Patients and Methods}

From 2003 to 2009, ten feet in nine patients (two males, seven females) were treated surgically with the Peterson and Newman bunion procedure. Pain, despite shoe wear modification, was the indication for surgery in all ten feet. The average age at operation was 23.6 years (range, 14-32 years). Metatarsus primus varus was present in all the patients. None of the patients had other problems like, ligamentous laxity, tight heel cord. The average length of follow up was 13.4 months (range 12-16 months). 


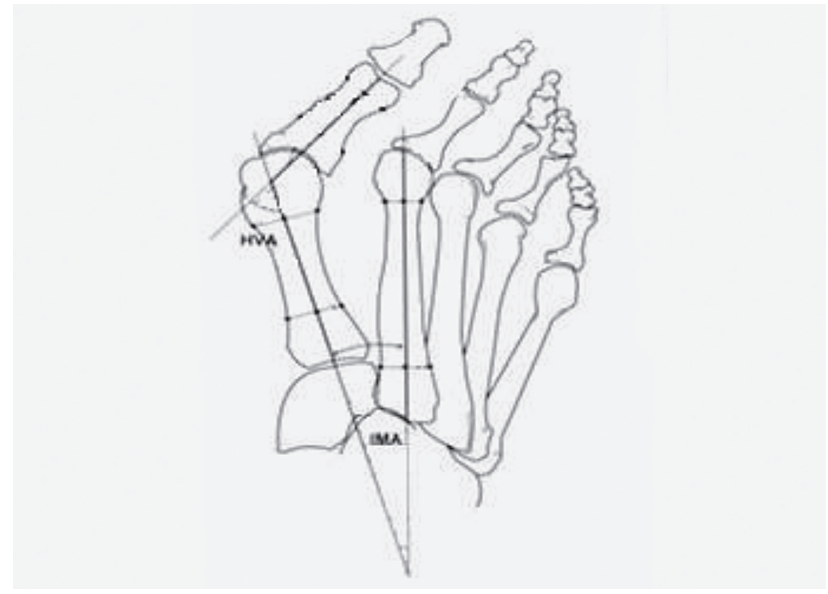

Fig. 1: Radiographic measurements: Hallux valgus angle is formed by the intersection of the longitudinal axes of the first metatarsal and the proximal phalanx. The first second intermetatarsal angle is formed by the intersection of the longitudinal axes of the first and second metatarsals.

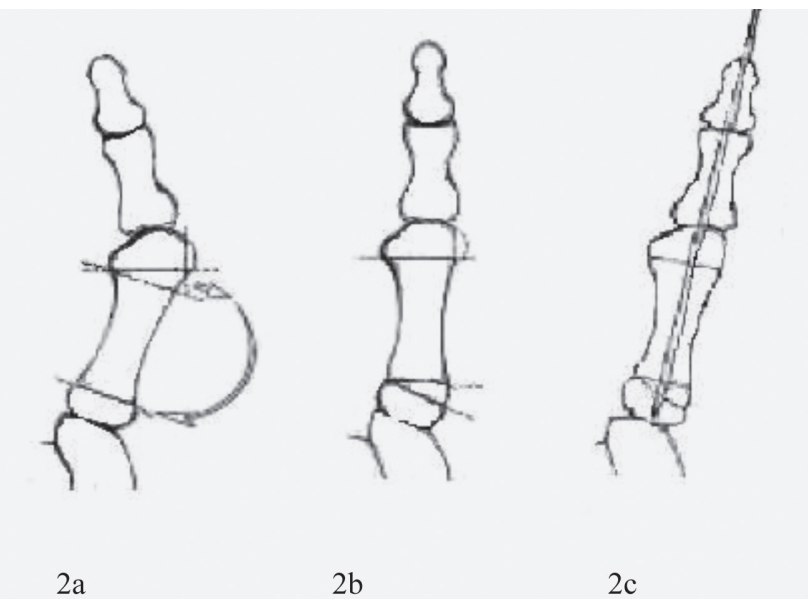

Fig. 2: Scheme of the double first metatarsal osteotomy.

Preoperative and postoperative evaluation included history, physical examination (including preoperative and postoperative assessment of MTP motion). Standing anteroposterior and lateral radiographs were taken preoperatively and during the final follow-ups. Radiographic assessment included the following: hallux valgus angle, intermetatarsal angle, relative lengths of the first and second metatarsal (33).

\section{Surgical Procedure}

A longitudinal incision was made over the medial side of the first metatarsal. The incision curved dorsally over the MTP joint onto the medial side of the base of the phalanx. The periosteum was divided longitudinally. A distally based,
Y shaped capsular flap was created and retracted distally. The diaphysis and both metaphyses were exposed subperiosteally on the dorsal, medial and volar surface. The medial prominence of the head of the first metatarsal was resected with preservation of the medial sulcus. A wedge of bone (with its base medial) was removed from the junction of the head and neck of the metatarsal using a transverse closing osteotomy (Fig. 2a). The angle of the apex wedge differed with the degree of deformity. The size of the wedge angle was exactly measured using preoperative radiographs.

A second transverse osteotomy was made perpendicular to the metatarsal about $1.5 \mathrm{~cm}$ distal to the proximal articular surface of the metatarsal. The proximal osteotomy was levered open with the osteotome. The bone wedge from prior distal osteotomy was inserted into the proximal osteotomy, creating an opening wedge medially to reduce the intermetatarsal angle (Fig. 2b). The distal osteotomy was then closed manually. A smooth Kirschner wire was driven from the tip of the toe proximally through both phalanges and the four parts of the first metatarsal (head, diaphysis, wedge graft and proximal base) to provide firm fixation and to prevent dorsiflexion and planterflexion of the metatarsal head (Fig. 2c).

The foot was supported with a plaster cast with regular dressings. The patients were advised not to bear weight for a period of 6 weeks. Thereafter Kirschner wire was removed and following which active mobilization of toe for 2-3 day and then gradual increase of weight bearing over a period of 2-3 weeks. Patients were advised to avoid any vigorous physical activity for a period of 3 months.

\section{Statistical Analysis}

The HV angle, first and second intermetatarsal angle, relative length of first and second metatarsal and range of movements of MTP at the time of final follow up was compared with preoperative value and the difference in the measured variable were analysed with Wilcoxon signed rank two tailed test. The level of significance was set at $p<0.05$.

\section{Results}

Clinical results for the 10 feet operated were satisfying as there were no complains of pain, joint stiffness, limping or functional impairment. Although there was some loss in the amount of dorsiflexion and plantarflexion of the great toe at the final follow up $4-6{ }^{\circ} \mathrm{Compared}$ to preoperative value, this did not cause any functional impairment. Patient and their parents were satisfied with the final clinical outcome.

The average preoperative HV angle was $36 \pm 3.6^{\circ}$ (range $30-41^{\circ}$ ). The average preoperative intermetatarsal angle was $14.5 \pm 2.32^{\circ}\left(\right.$ range $\left.12-18^{\circ}\right)$. The physes were closed in all the patients at the time of operation. There were no intraoperative complications. All the osteotomies healed primarily without any infection. The short leg cast and Kirschner wire were removed after six weeks and the patients were mobilized slowly in a period of 6-8 weeks. There were 

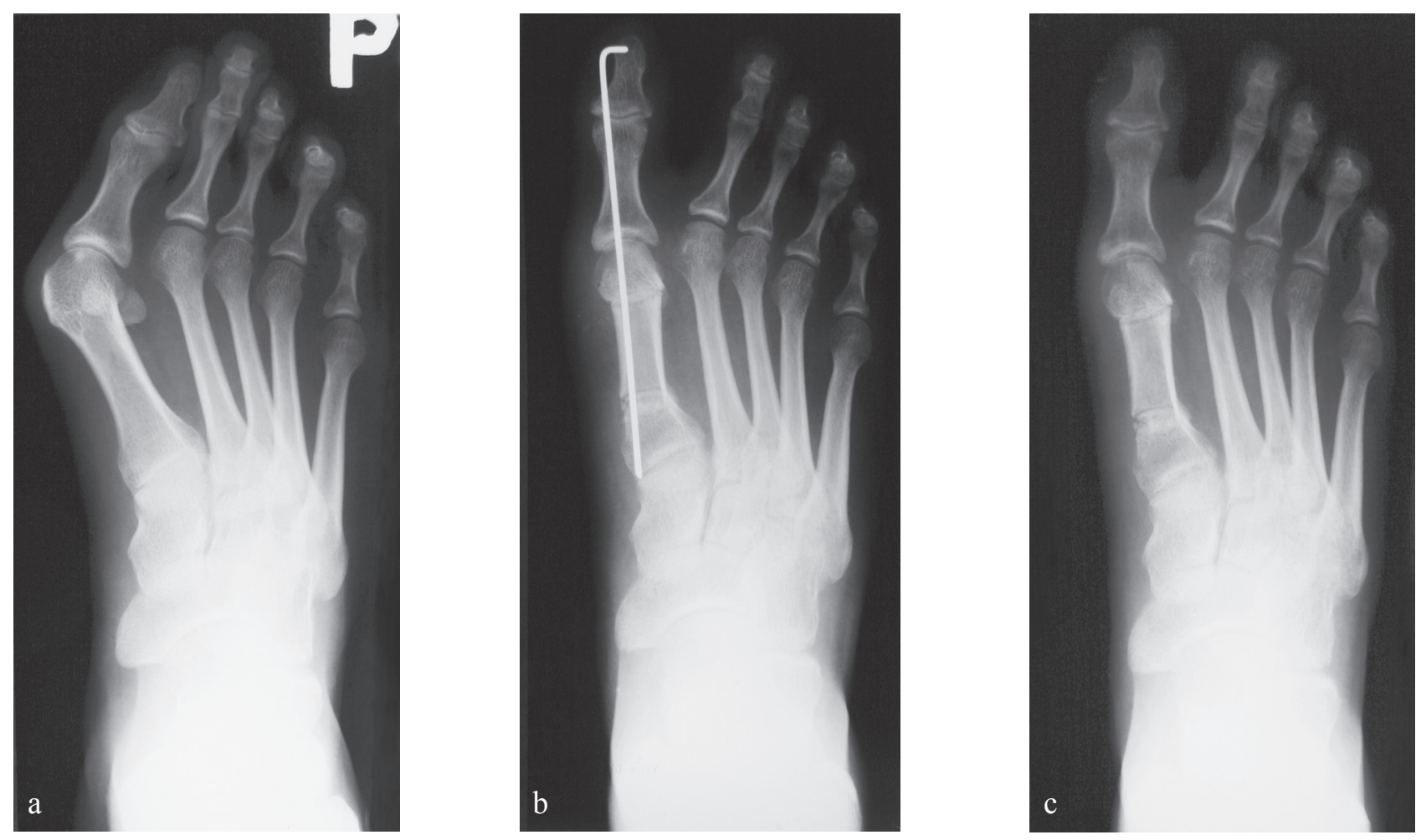

Fig. 3: a) preoperative x-ray of a 23-year-old patient with HV and metatarsus primus of the right foot, b) postoperative x-ray after correction of the deformity, c) X-ray taken on 6th week after removal of Kirschner wire.

no avascular changes of the metatarsal head and no hallux varus.

At the final follow up the average $\mathrm{HV}$ angle was reduced to $14.6^{\circ} \pm 3.40^{\circ}$ (range $9-20^{\circ}$ ) and the average intermetatarsal angle was reduced to $4.8^{\circ} \pm 2.44^{\circ}$ (range $1-8^{\circ}$ ). The average first metatarsal length in relation to the second metatarsal was reduced by $0.5 \pm 1.26 \mathrm{~mm}$ (range $1-3 \mathrm{~mm}$ ). The mean dorsiflexion decreased from $64^{\circ} \pm 10^{\circ}$ (range $10-90^{\circ}$ ) preoperatively to $58^{\circ} \pm 9^{\circ}$ (range $0-90^{\circ}$ ) at the time of final follow up, and the mean plantarflexion decreased from $17^{\circ} \pm$ $11^{\circ}\left(\right.$ range $\left.0-45^{\circ}\right)$ preoperatively to $13^{\circ} \pm 12^{\circ}\left(\right.$ range $\left.0-40^{\circ}\right)$ at the time of final follow up.

\section{Discussion}

Adolescent hallux valgus associated with a bunion is a lateral deviation of the great toe in the transverse plane of the MTP joint. The deformity usually occurs bilaterally, generally affects females twice as often as males, and the incidence varies depending on the population being studied and cultural practices, such as footwear use $(10,34)$. HV has a multifactorial etiology including extrinsic and intrinsic causes $(4,5,17,36)$. Extrinsic factors that may play a role include persistent use of shoes with narrow toe box and elevated heels $(15,16,27)$ and the presence of a subtle underlying neurological disorder, such as cerebral palsy
Tab. 1: Clinical and radiographic data. The values are given as mean, standard deviation and range. Wilcoxon signed rank two tailed test was used for statistical evaluation.

\begin{tabular}{|l|c|c|c|}
\hline & Preoperative & Final follow up & P value \\
\hline HV angle & $\begin{array}{c}36^{\circ} \pm 3.6^{\circ} \\
\text { range } 30-41^{\circ}\end{array}$ & $\begin{array}{c}14.6^{\circ} \pm 3.40^{\circ} \\
\text { range } 9-20^{\circ}\end{array}$ & $<0.0001$ \\
\hline $\begin{array}{l}\text { Intermetatarsal } \\
\text { angle }\end{array}$ & $\begin{array}{c}14.5^{\circ} \pm 2.32^{\circ} \\
\text { range } 12-18^{\circ}\end{array}$ & $\begin{array}{c}4.8^{\circ} \pm 2.44^{\circ} \\
\text { range } 1-8^{\circ}\end{array}$ & $<0.0001$ \\
\hline $\begin{array}{l}\text { Metatarsal } \\
\text { length (mm) }\end{array}$ & $\begin{array}{c}0.5 \pm 1.26 \mathrm{~mm} \\
\text { range } 1-3 \mathrm{~mm}\end{array}$ & \\
\hline $\begin{array}{l}\text { MTP } \\
\text { dorsiflexion }\end{array}$ & $\begin{array}{c}64^{\circ} \pm 10^{\circ} \\
\text { range } 10-90^{\circ}\end{array}$ & $\begin{array}{c}58^{\circ} \pm 9^{\circ} \\
\text { range } 0-90^{\circ}\end{array}$ & 0.02 \\
\hline $\begin{array}{l}\text { MTP } \\
\text { plantarflexion }\end{array}$ & $\begin{array}{c}17^{\circ} \pm 11^{\circ} \\
\text { range } 0-45^{\circ}\end{array}$ & $\begin{array}{c}13^{\circ} \pm 12^{\circ} \\
\text { range } 0-40^{\circ}\end{array}$ & 0.02 \\
\hline
\end{tabular}

(15). Footwear is thought to be an aggravating factor rather than a causal factor as not all individuals who wear poor footwear develop HV. Intrinsic factors include metatarsus primus varus (14), an oblique first metatarsal-medial cuneiform articulation (21), a long first metatarsal $(31,32)$, hypermobility of first tarsometatarsal joint $(8,22)$ and generalized ligamentous laxity with pes planus (31). Heredity is considered as one of the major predisposing factors for 
HV deformity (9). It is unclear whether metatarsus primus is the primary deformity or is secondary to hallux valgus deformity (11). As many as $50 \%$ of adolescent $\mathrm{HV}$ patients can also have flexible flat feet and ligamentous laxity (19).

In younger patients an attempt is made to restore the foot to normal. Failure rate, recurrence rate (25) and complication rate are much higher and serious in adolescents (34). There is a greater chance of inadequate correction at the MTP joint and residual HV deformity after bunion surgery, if residual deformity exists at intermetatarsal level (19). According to Scranton and Zuckerman there is no recurrent deformity in patients whose intermetatarsal angle was corrected to $4^{\circ}$ or less (31). The average intermetatarsal angle during follow was $4.8^{\circ}$ (range $1-8^{\circ}$ ). Correction of IMA is the crucial principle in this procedure and this prevents the recurrence of $\operatorname{HV}(1,26)$. In our study there were no recurrences of $\mathrm{HV}$ in these patients.

There were no cases of hallux varus in our study, a complication occurring due to over-correction. An incidence of about $13 \%$ hallux varus was reported by Peterson (26), a complication that should be avoided as it leads to progressive varus angulations and patient dissatisfaction.

The Peterson and Newman procedure addresses all of the basic components of the deformity. The valgus alignment of the articular surface of the metatarsal head is corrected with a closing wedge osteotomy, and the metatasus primus varus is corrected with a basal opening wedge osteotomy with the use of bone from the distal osteotomy. This procedure has the benefit of maintaing the same joint surface relationships of the metatarsal and opposing phalanx. The entire great toe may be rotated at the site of distal closing wedge osteotomy if toe malrotation is a problem. This technique does not change the length of the first metatarsal since the same piece of bone is used to closing and opening wedge osteotomies.

Using the method of Hardy and Clapham (12) the relative lengths of the first and second metatarsals was calculated, and found equal in $80 \%$ of the feet and shortened in $20 \%$. Relative length within $1 \mathrm{~mm}$ was considered equal due to inaccuracies in measurement methods. Shortening of first ray about $<0.5 \mathrm{~cm}$ is acceptable (4). A closed wedge osteotomy will shorten the metatarsal whereas an open wedge will lengthens it (2). Excessive shortening of the first metatarsal may transfer the pressure to the head of second metatarsal leading to prominence and pain of second metatarsal (26, 35 ), but lengthening the bone may increase the pressure in the intra-articular MTP joint and cause arthrosis and stiffness (26). Lengthening of first metatarsal also results in soft tissue tension and risk of recurrence (24).

Stiffness of the MTP joint after bunion surgery can lead to unsatisfactory results (20). The mean dorsiflexsion of MTP joint during gait is $42^{\circ}$ as described by Nawoczenski et al. (24). In our study even though the patients had some mild loss of range of movements at the MTP joints compared to preoperative value, it did not cause any sort of functional impairment.
We acknowledge that the major limitations of our study are small group of patients and the short to intermediate term outcome. In addition the retrospective nature of the study has it inherent deficiency. A long term follow up would be ideal to see if these results would be reproducible. However we feel it is useful to report our short to intermediate term outcome as the outcome has a clear trend.

\section{Conclusion}

The double metatarsal osteotomy for the treatment of $\mathrm{HV}$ is technically a precise procedure and allows excellent correction of both the metatarsus primus varus and hallux valgus without changing the anatomy of the MTP articulation. It has low rate of recurrence of deformity. We had an excellent outcome in 10 feet in our study without residual deformity or complication. We believe that the Peterson and Newman double metatarsal osteotomy is a reliable procedure in cases of severe hallux valgus deformity in adolescent and young adults.

\section{References}

1. Aronson J, Nguyen LL, Aronson EA. Early results of the modified Peterson bunion procedure for adolescent hallux valgus. J Pediatr Orthop 2001; 21(1): 65-9.

2. Bordelon RL. Evaluation and operative procedures for hallux valgus deformity. Orthopedics 1987; 10: 81-96.

3. Canale PB, Aronsson DD, Lamont RL, et al. The Mitchell procedure for the treatment of adolescent hallux valgus. J Bone Joint. Surg [Am] 1993; 75: 1610-18.

4. Coetzee JC, Resig SG, Kuskowski M, Saleh KJ. The Lapidus Procedure as Salvage After Failed Surgical Treatment of Hallux Valgus. J Bone Joint Surg 2004; 86: $30-36$.

5. Coughlin MJ. Juvenile Hallux valgus: Etiology and treatment. Foot Ankle Int 1995; 16: 682-97.

6. Easley ME, Trnka HJ. Current concept review: Hallux valgus part 1: pathomechanisms, clinical assessment and non operative management. Foot Ankle Int 2007; 28: 748-58.

7. George HL, Casaletta J, Unnikrishnan PN. Outcome of scarf osteotomy in adolescent hallux valgus. J Child Orthop 2009; 3: 185-90.

8. Glasoe WM, Allen MK, Saltzman CL. First ray dorsal mobility in relation to hallux valgus deformity and first intermetatarsal angle. Foot Ankle Int 2001; 22: 98-101.

9. Glynn MK, Dunlop JB, Fitzpatrick D. The Mitchell distal metatarsal osteotomy for hallux valgus. J Bone Joint Surg [Br] 1980; 12B: 188-91.

10. Helal B. Surgery for adolescent hallux valgus. Clin Orthop 1981; 157: 50-63.

11. Hardy RH, Clapham JCR. Hallux valgus. Predisposing and anatomical causes. Lancet 1952; 1: 1180-3.

12. Hardy RH, Clapham JCR. Observations on hallux valgus. J Bone Joint Surg Am 1945; 27: 376-91.

13. Kilmartin TE, Barrington RL, Wallace WA. A controlled prospective trial of a foot orthosis for juvenile hallux valgus. J Bone Joint Surg Br 1994; 76: 210-14.

14. Kilmartin TE, Barrington RL, Wallace WA. Metatarsus primus varus. A statistical study. J. Bone and Joint surg 1991; 73(6): 937-40.

15. Koop SE, Adolescent hallux valgus. The childs foot and ankle. Raven press, New York 1992; 417-23.

16. Lam SL, Hodgson AR. A comparison of foot from among the non-shoe and shoe wearing Chinese population. J Bone Joint Surg [Am] 1958; 40A: 1058-62.

17. Lechler P, Feldmann C, Kock FX, Schaumburger J, Grifka J, Handel M. Clinical outcome after Chevron-Akin double osteotomy versus isolated Chevron procedure: a prospective matched group analysis. Arch Orthop Trauma Surg. 2011 Aug 28 .

18. Lutonsky M, Sponer P. Personal experience with the basal wedge closed osteotomy of the first metatarsus in hallux valgus. Acta Chir Orthop Traum Čech 2002; 69: $45-8$.

19. Mann RA, Coughlin MJ. Adult hallux valgus. In Coughlin MJ, Mann RA, editors. Surgery of foot and ankle. Vol. 1, 7th ed. St Louis: Mosby 1999: 150-269.

20. McDonald MG, Stevens DB. Modified Mitchell bunionectomy for management of adolescent hallux valgus. Clin Orthop. 1996; 332: 163-9.

21. Meehan PL. Adolescent Bunion. Lovells and Winters Pediatric Orthopedics, Lippincott JB, Philadelphia 1993; 3: 983-90. 
22. Myerson MS, Badekas A. Hypermobility of first ray. Foot Ankle Clin 2000; 5 469-84.

23. Murawski CD, Egan CJ, Kennedy JG. A rotational scarf osteotomy decrease troughing when treating hallux valgus. Clin Orthop Relat Res. 2011; 469(3) $847-53$.

24. Nawoczenski DA, Baumhauer JF, Umberger BR. Relationship between clinical measurements and motion of the first metatarsal joint during gait. J Bone Joint Surg Am 1999; 81: 370-6.

25. Okuda R, Kinoshita M, Yasuda T, et al. The shape of the lateral edge of firs metatarsal head as a risk factor for recurrence of hallux valgus. J Bone Joint Surg [Am] 2007; 89: 2163-72.

26. Peterson HA, Newman SR. Adolesecent bunion deformity treated with double osteotomy and longitudinal pin fixation of first ray. J Pediatr Orthop 1993; 13: 80-4.

27. Robison AHN, Limber JP. Modern concepts in treatment of hallux valgus. J Bone Joint Surg 2005; 87B: 1038-45.

28. Salamao O. Hallux valgo: etiologia e tratamento. Rev Bras Orthop 2005; 40: $147-52$.

29. Sammareo VJ, Nicholos R. Orthotic management for disorders of hallux. Foot Ankle Clin 2005; 10: 191-209.
30. Sammareo VJ. Surgical correction of moderate and severe hallux valgus. An instructional course lecture. AAOS. J Bone Joint Surg [Am] 2007; 89: 2520-31.

31. Scranton PE, Zuckerman JD. Bunion surgery in adolescents: Results of surgical treatment. J Pediatr Orthop 1984; 4; 39-43.

32. Scranton PE. Current concept review. Principles in bunion surgery. J. Bone Joint Surg 1983; 65(A): 1026-8.

33. Shima $H$, Okuda R, Yasuda T, Jotuku T et al. Radiographic measurement in patients with hallux valgus before and after proximal crecentric osteotomy. J Bone Joint Surg [Am] 2009; 91: 1369-76.

34. Shine IB. Incidence of hallux valgus in a partially shoe-wearing community. $\mathrm{Br}$ Med J 1965; 26: 1(5451): 1648-50.

35. Trnka HJ, Hofstaetter SG, Hofstaetter JG. Intermediate term results of Ludloff Osteotomy in one hundred and eleven feet. J Bone Joint Surg [Am] 2008; 90: $531-9$.

36. Unal AM, Baran O, Uzun B, Turan AC. Comparison of screw fixation stabilities of first metatarsal shaft osteotomies; A biomechanical study. Acta Orthop Traumato Ture 2010; 44(1): 70-75.

Received: $15 / 11 / 2011$

Accepted in revised form: 22/02/2012

\section{Corresponding author:}

Pradeep George Mathew, M.D., University Hospital, Sokolská 581, 50005 Hradec Králové, Department of Orthopaedic Surgery; e-mail: drpradeepgeorge@yahoo.com 